Supplement of Ocean Sci., 14, 813-826, 2018

https://doi.org/10.5194/os-14-813-2018-supplement

(C) Author(s) 2018. This work is distributed under

the Creative Commons Attribution 4.0 License.

(c) (1)

Supplement of

\title{
Transport of FNPP1-derived radiocaesium from subtropical mode water in the western North Pacific Ocean to the Sea of Japan
}

Yayoi Inomata et al.

Correspondence to: Yayoi Inomata (yinomata@se.kanazawa-u.ac.jp)

The copyright of individual parts of the supplement might differ from the CC BY 4.0 License. 


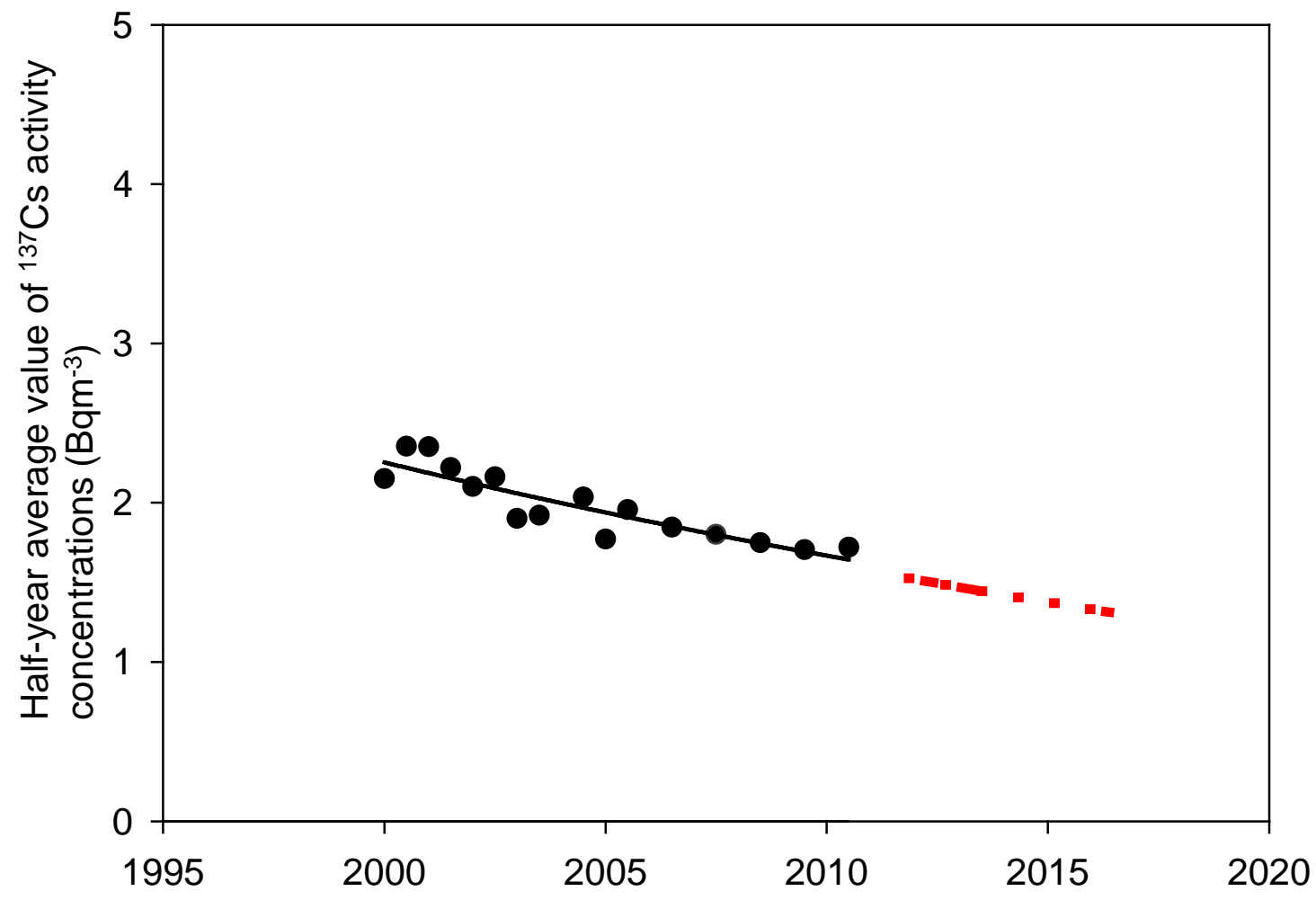

Fig. S1. The half-year average value of ${ }^{137} \mathrm{Cs}$ activity concentrations from 2000 to 2010 (black circle and line). Based on the exponential curve fitting, ${ }^{137} \mathrm{Cs}$ activity concentrations after 2010 were extrapolated to 2016 (red broken line). 

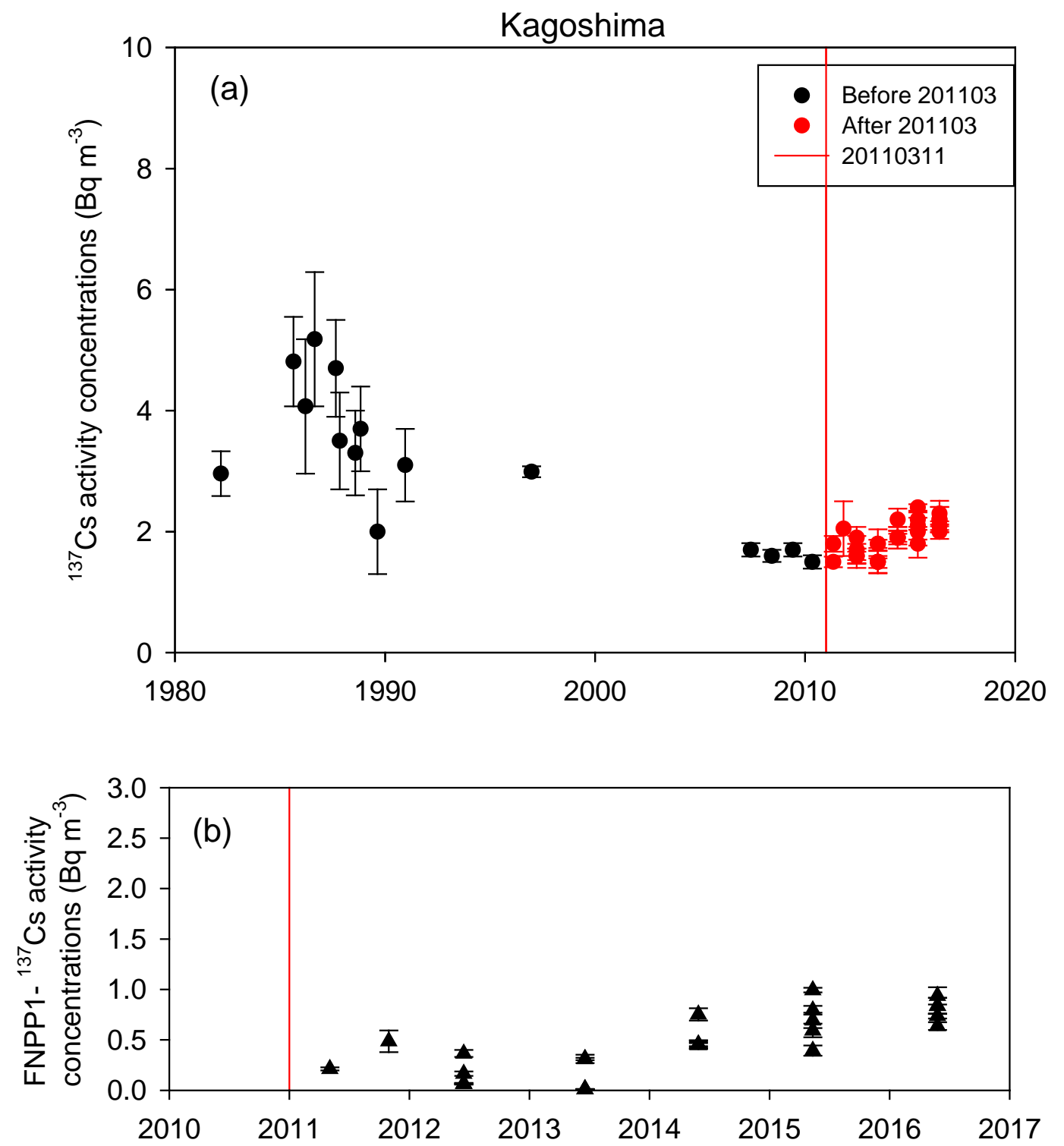

Fig. S2. Time variation of (a) ${ }^{137} \mathrm{Cs}$ activity concentrations from 1980 to 2016, (b) FNPP1- ${ }^{137} \mathrm{Cs}$ activity concentrations at the station Kagoshima. The value was decay corrected to $11^{\text {th }}$ March 2011.Vertical red line mean the FNPP1 accident day (11 March 2011). 

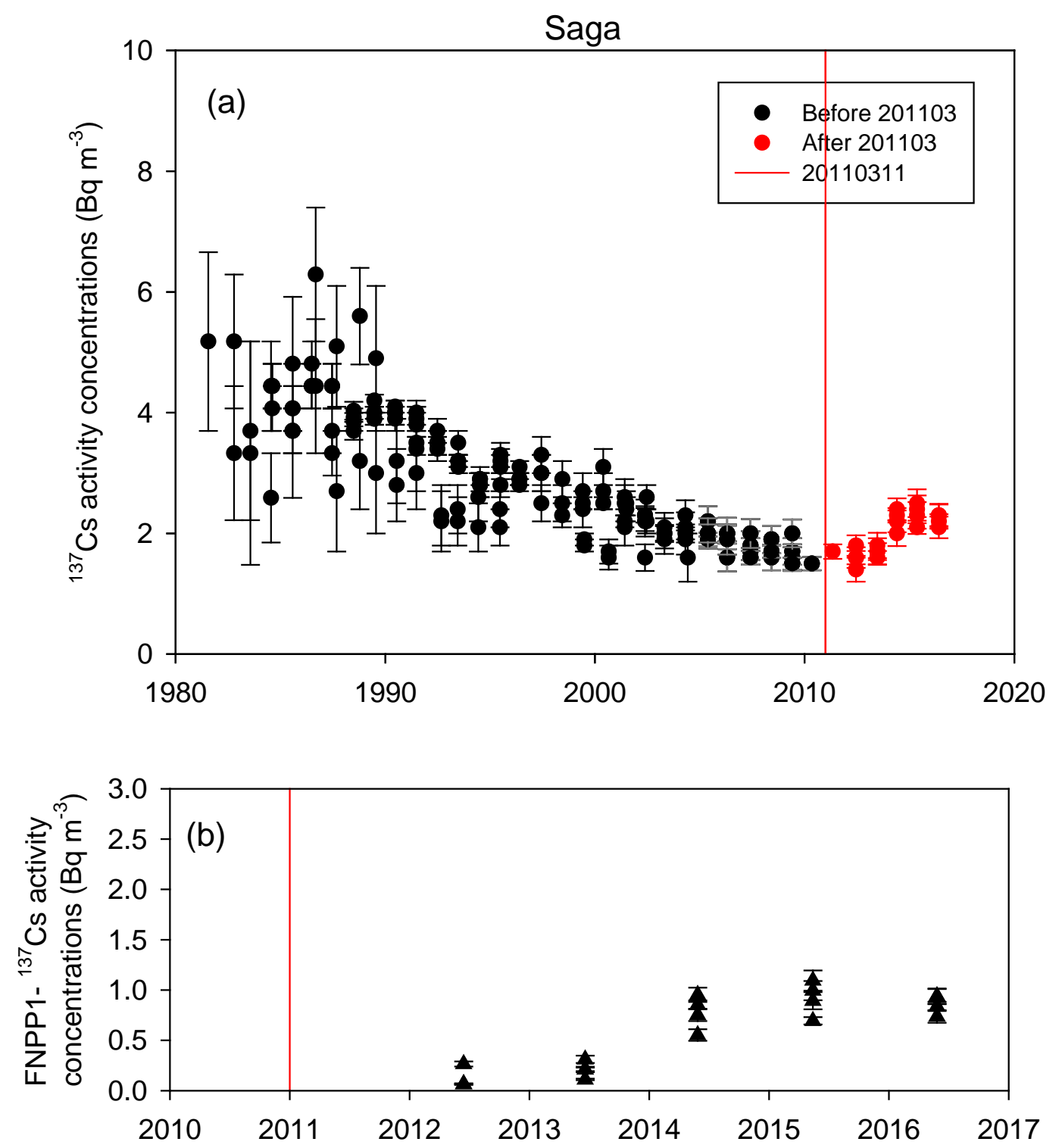

Fig. S3. Time variation of (a) ${ }^{137} \mathrm{Cs}$ activity concentrations from 1980 to 2017, (b) FNPP1- ${ }^{137} \mathrm{Cs}$ activity concentrations at the station Saga. The value was decay corrected to $11^{\text {th }}$ March 2011.Vertical red line mean the FNPP1 accident day (11 March 2011). 

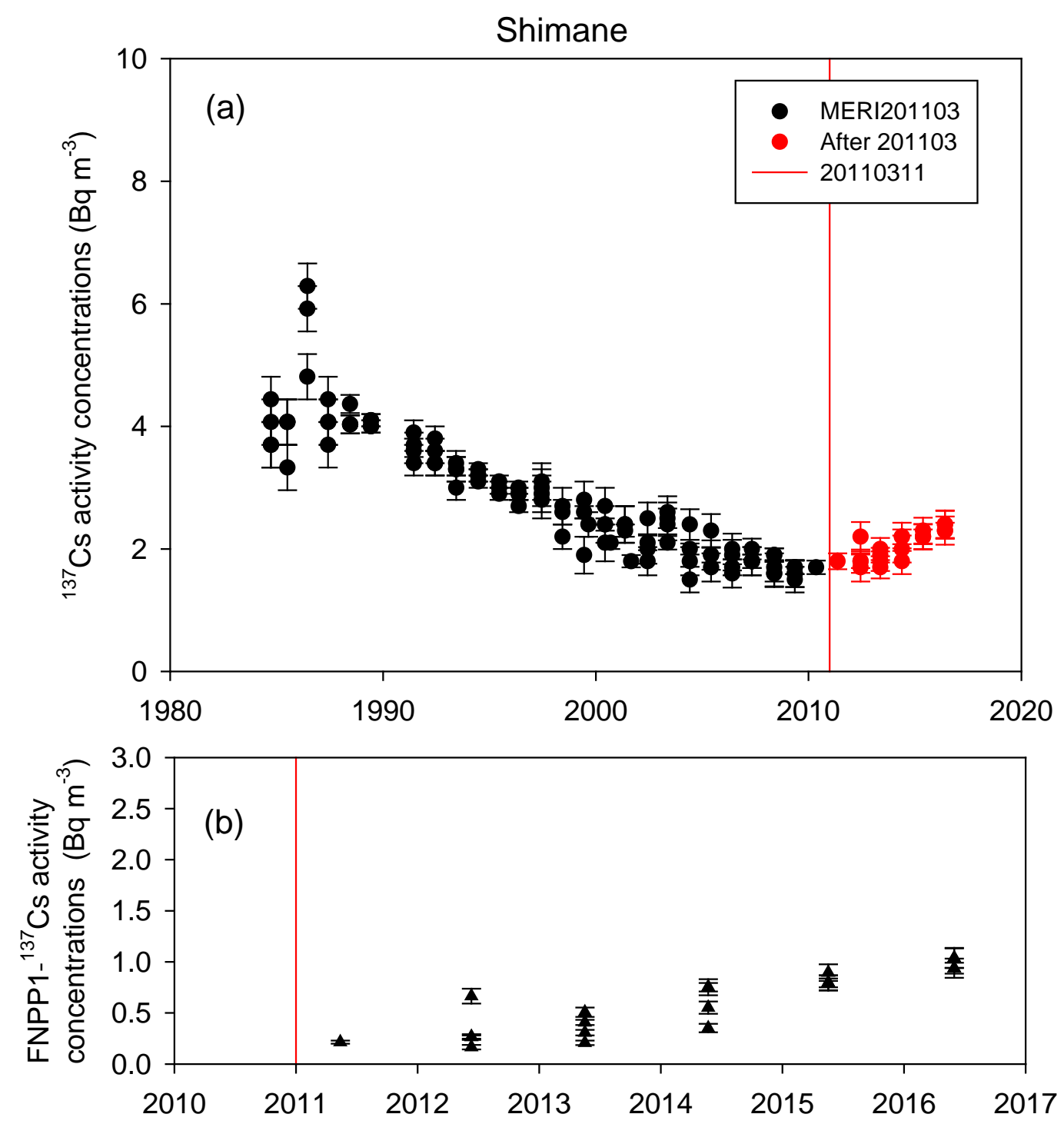

Fig. S4. Time variation of (a) ${ }^{137} \mathrm{Cs}$ activity concentrations from 1980 to 2017, (b) FNPP1-137Cs activity concentrations at the station Shimane. The value was decay corrected to $11^{\text {th }}$ March 2011.Vertical red line mean the FNPP1 accident day (11 March 2011). 

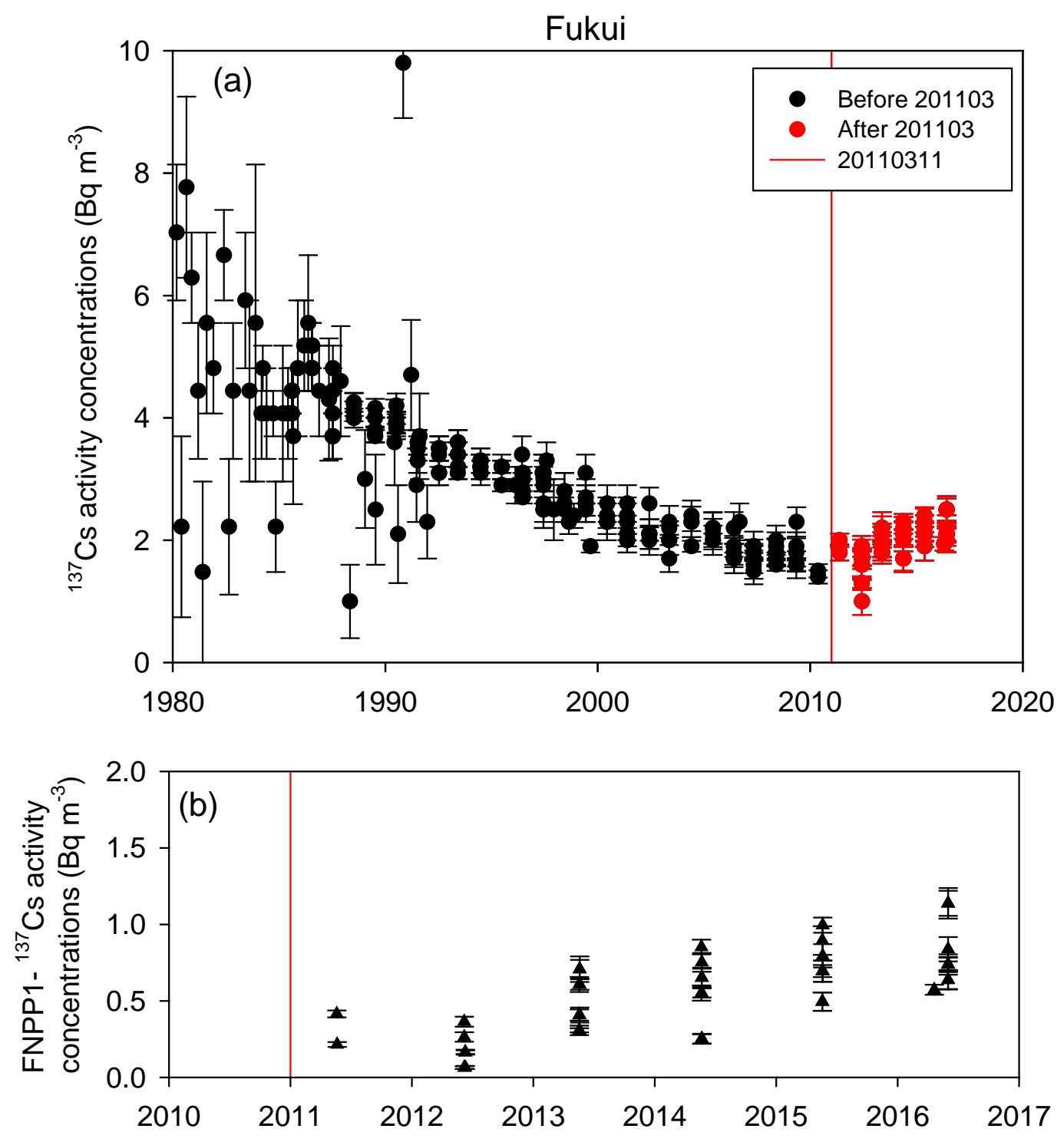

Fig. S5. Time variation of (a) ${ }^{137}$ Cs activity concentrations from 1980 to 2017, (b) FNPP1-137Cs activity concentrations at the station Fukui. The value was decay corrected to $11^{\text {th }}$ March 2011 .Vertical red line mean the FNPP1 accident day (11 March 2011). 

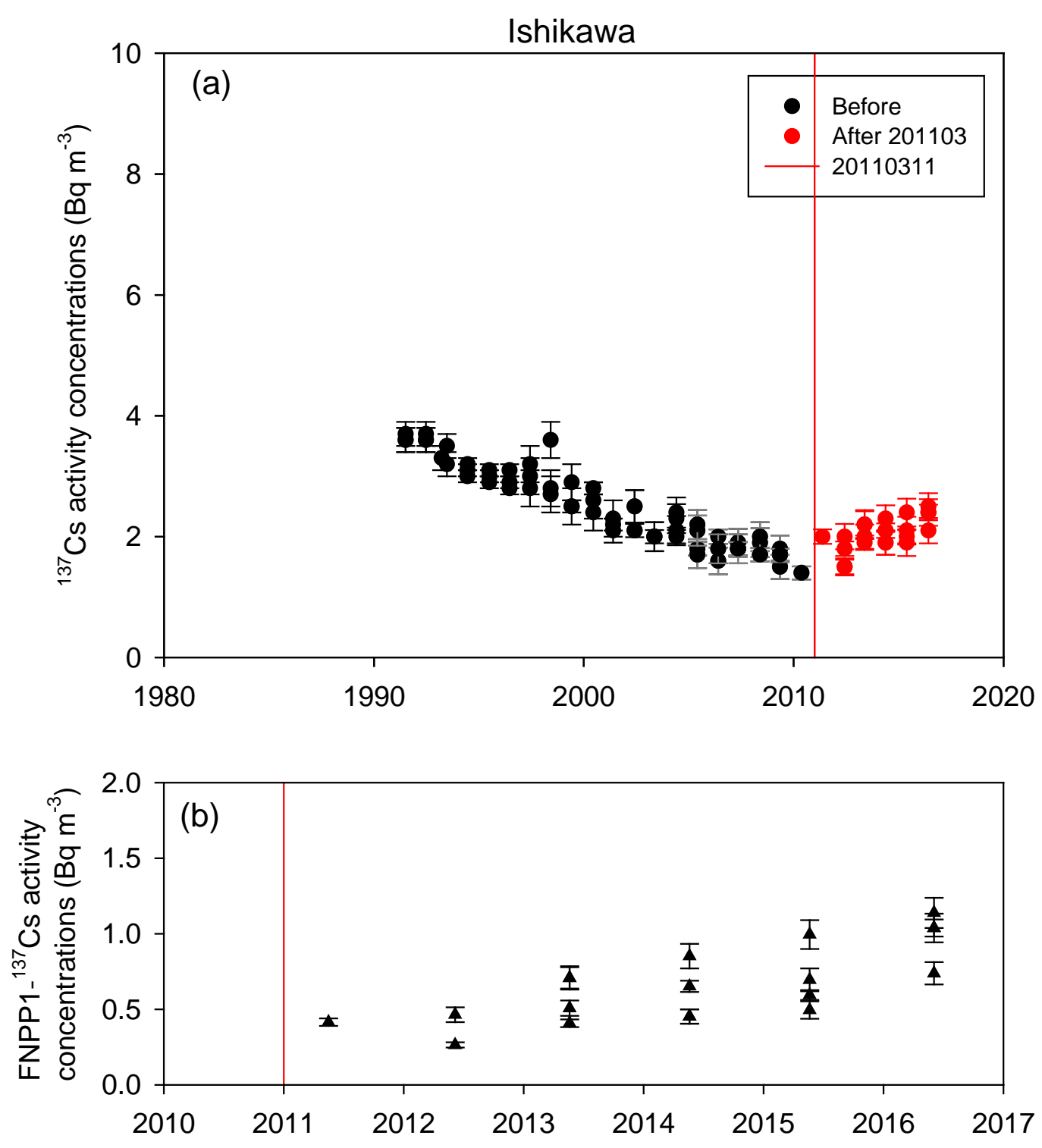

Fig. S6. Time variation of (a) ${ }^{137}$ Cs activity concentrations from 1980 to 2020, (b) FNPP1${ }^{137} \mathrm{Cs}$ activity concentrations at the station Ishikawa. The value was decay corrected to $11^{\text {th }}$ March 2011. Vertical red line mean the FNPP1 accident day (11 March 2011). 

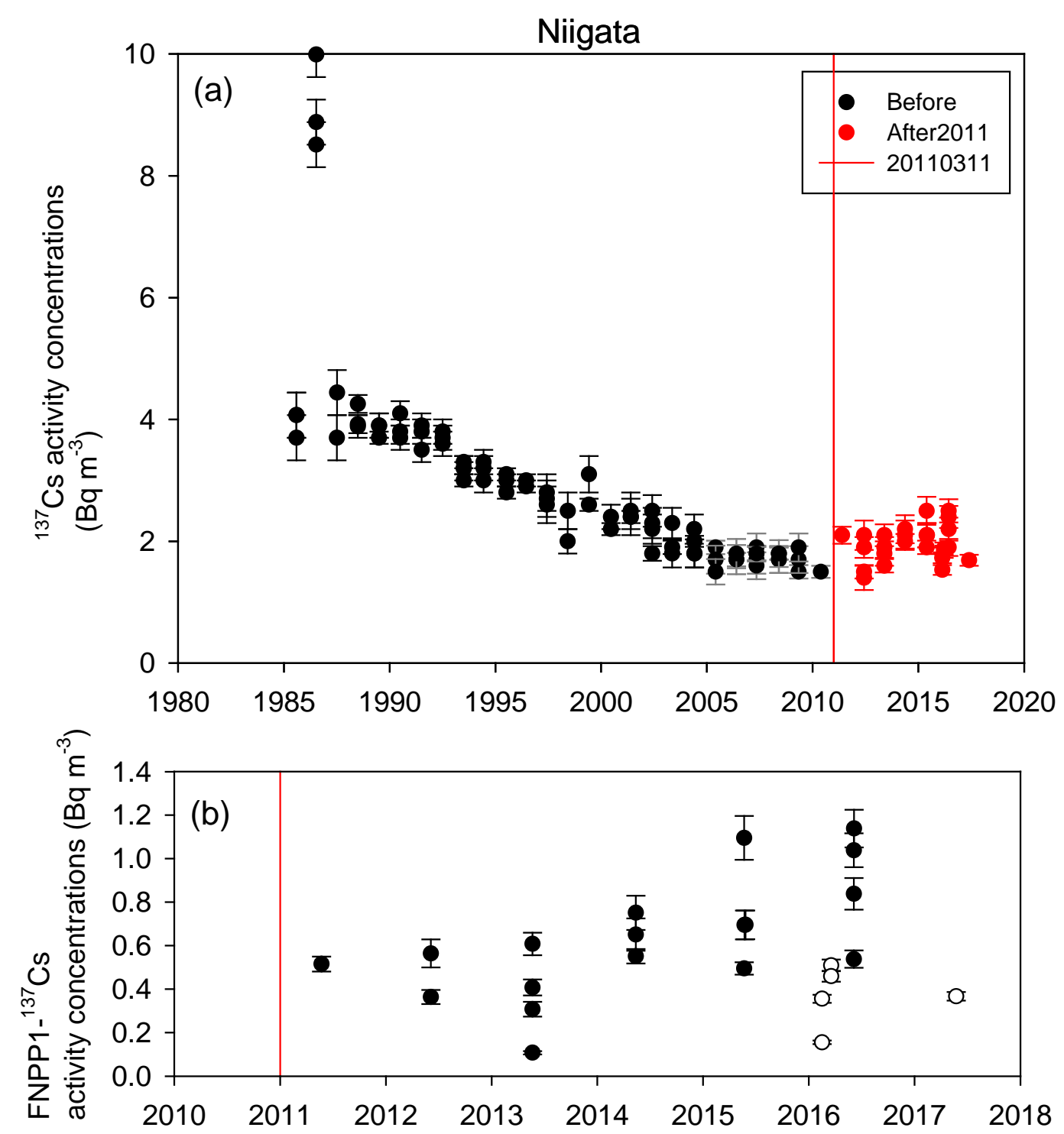

Fig. S7. Time variation of (a) ${ }^{137} \mathrm{Cs}$ activity concentrations from 1980 to 2017, (b) FNPP1- ${ }^{137} \mathrm{Cs}$ activity concentrations at the station Niigata. The value was decay corrected to $11^{\text {th }}$ March 2011.Vertical red line mean the FNPP1 accident day (11 March 2011). In (b), black circles are Japanese government monitoring data, and white circles are measured in this study. 
Aomori area
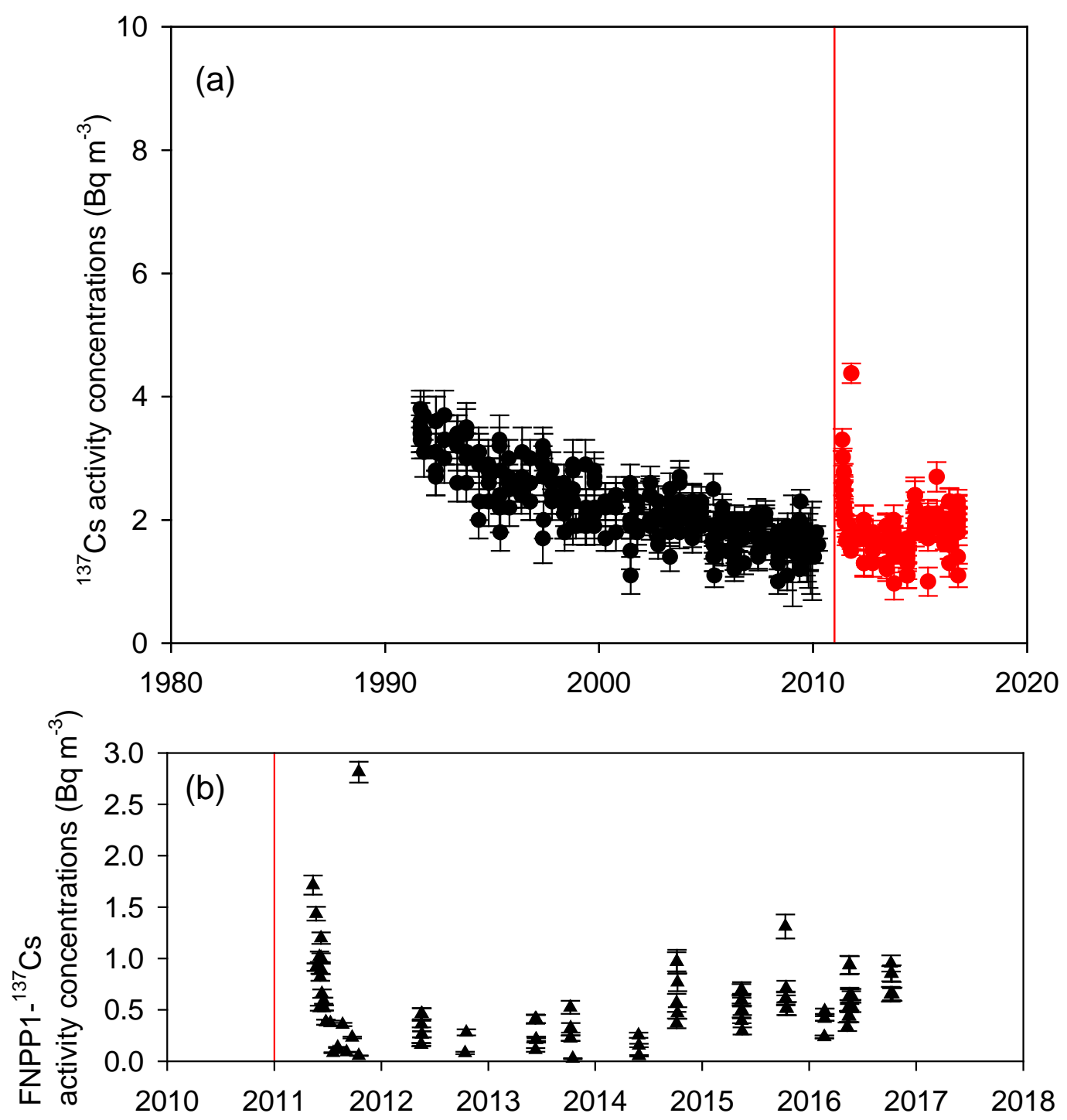

Fig. S8. Time variation of (a) ${ }^{137} \mathrm{Cs}$ activity concentrations from 1980 to 2017, (b) FNPP1- ${ }^{137} \mathrm{Cs}$ activity concentrations at the station Aomori. The value was decay corrected to $11^{\text {th }}$ March 2011.Vertical red line mean the FNPP1 accident day (11 March 2011). 
Tomari
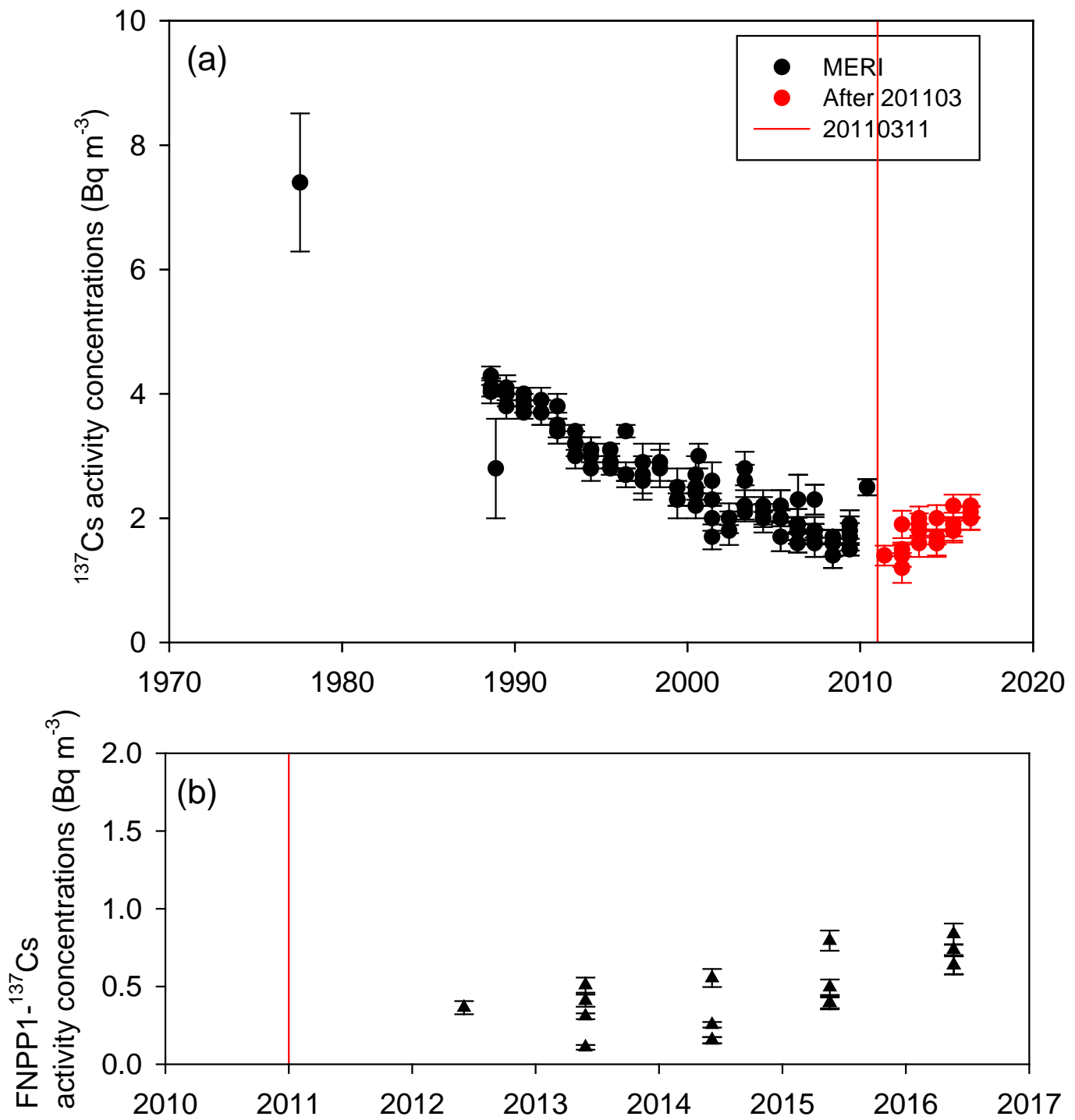

Fig. S9. Time variation of (a) ${ }^{137} \mathrm{Cs}$ activity concentrations from 1970 to 2017, (b) FNPP1-137Cs activity concentrations at the station Tomari. The value was decay corrected to $11^{\text {th }}$ March 2011. Vertical red line mean the FNPP1 accident day (11 March 2011). 


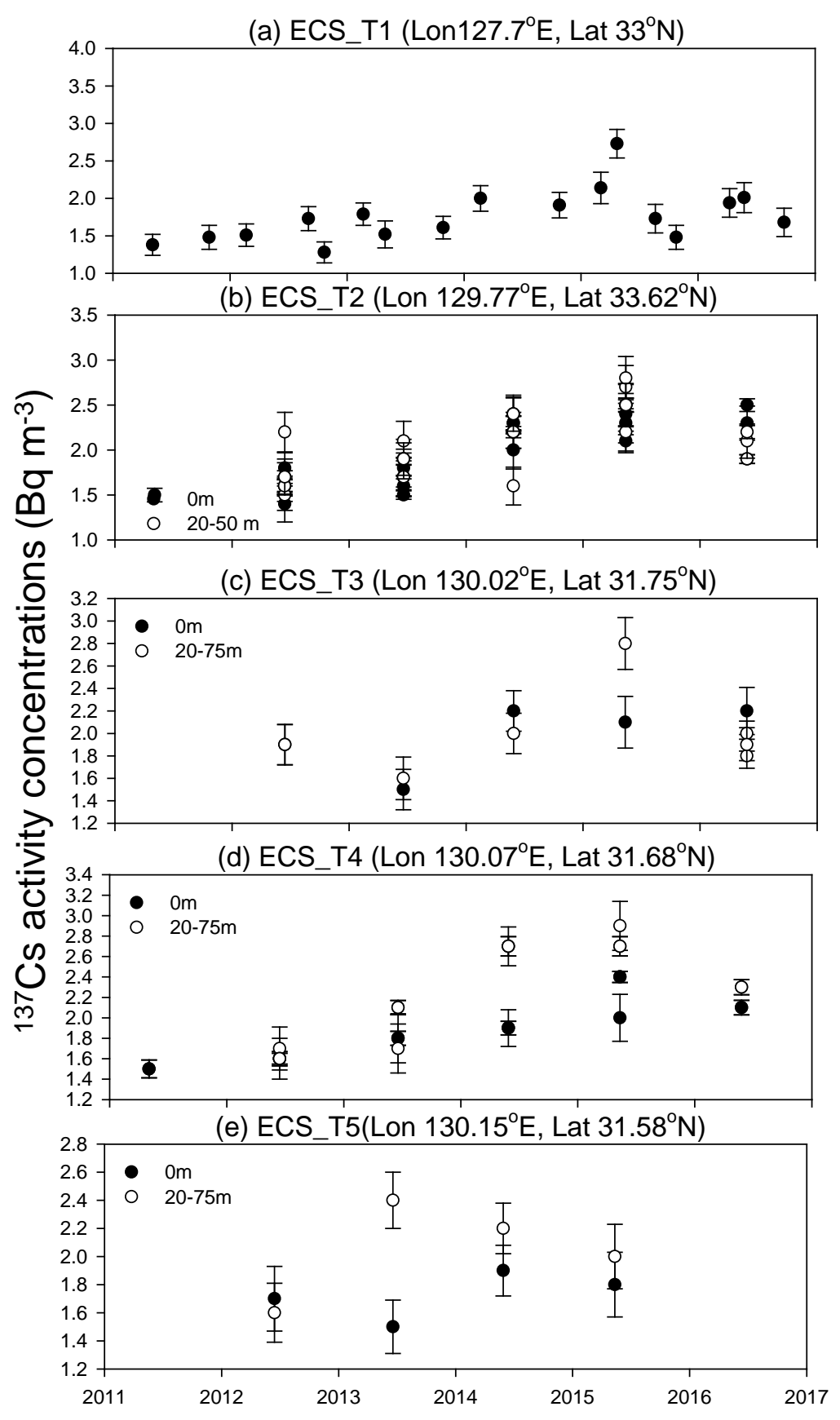

Fig. S10. Temporal variations of ${ }^{137} \mathrm{Cs}$ activity concentrations at the five stations in the ECS. (a) T1: Longitude $127.7^{\circ} \mathrm{E}$, Latitude $33^{\circ} \mathrm{N}$, (b) $\mathrm{T} 2$ : Longitude $129.77^{\circ} \mathrm{N}$, Latitude $33.62^{\circ} \mathrm{N}$, (c) T3: Longitude $130.02^{\circ} \mathrm{E}$, latitude $31.75^{\circ} \mathrm{N}$, (d) T4: Longitude $130.07^{\circ} \mathrm{E}$, Latitude $31.68^{\circ} \mathrm{N}$, (e) T5: Longitude $130.15^{\circ} \mathrm{N}$, Latitude $31.58^{\circ} \mathrm{N}$. These are monitoring stations denoted as triangle with arrows in Fig. SI12. 
(a) Kagoshima
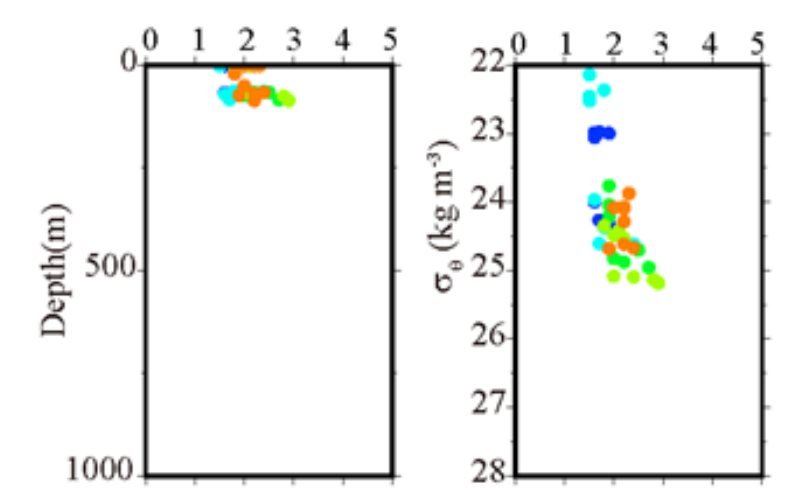

${ }^{137} \mathrm{Cs}$ (b) Saga

${ }^{137} \mathrm{Cs}$ activity concentrations $\left(\mathrm{Bqm}^{-3}\right)$
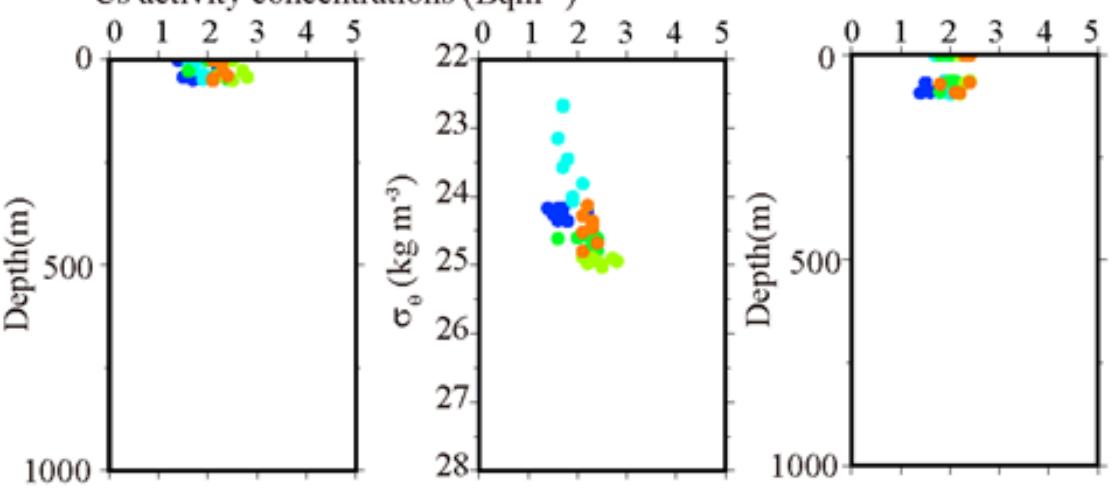

(e) Ishikawa

(d) Fukui ${ }_{5} \begin{array}{llllll}0 & 1 & 2 & 3 & 4 & 5\end{array}$
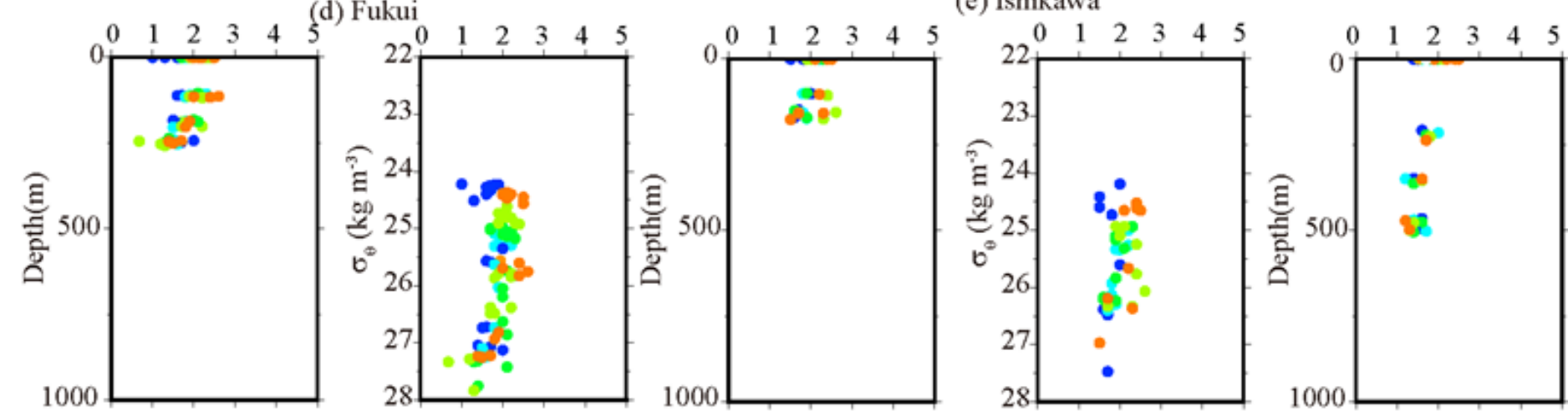

(f) Niigata

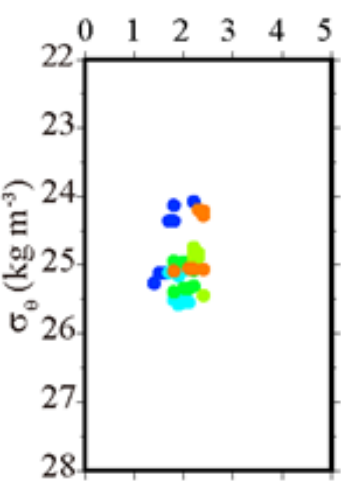

0

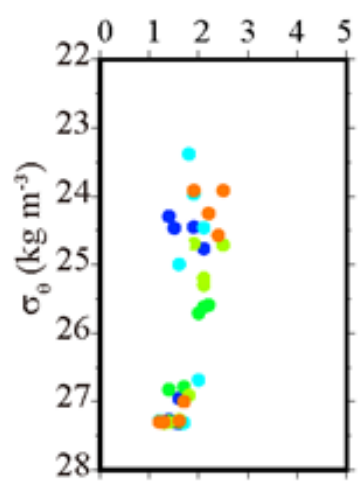

(h)Tomari $\begin{array}{llllll}0 & 1 & 2 & 3 & 4 & 5\end{array}$

(g) Aomori
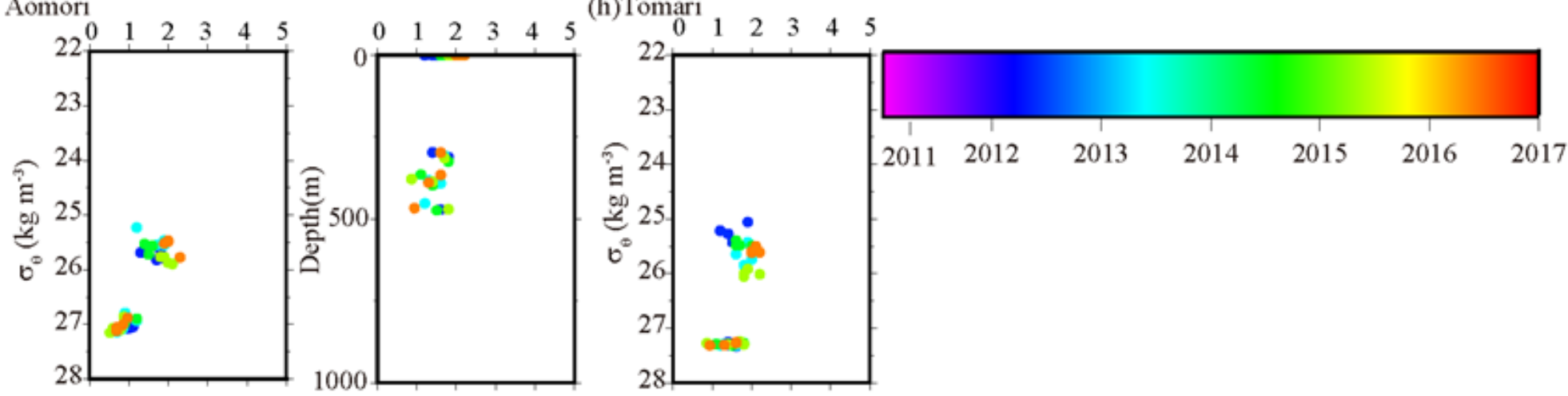

(continued) 


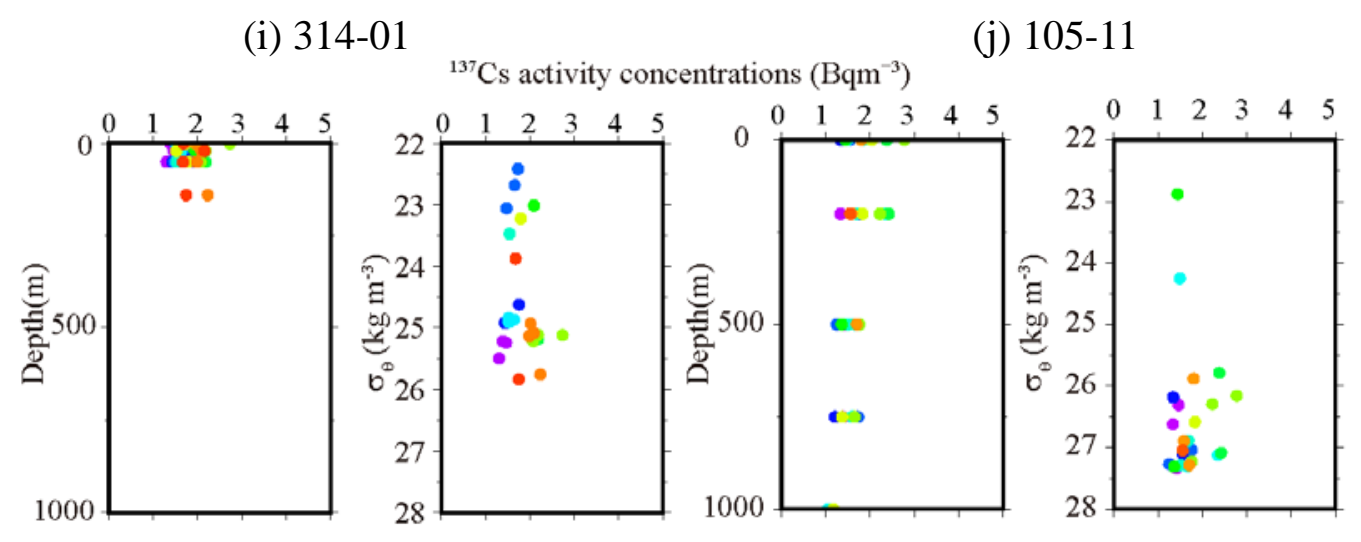

Figure S11: Vertical distributions of ${ }^{137} \mathrm{Cs}$ activity concentrations against depth and potential water density anomaly $\left(\sigma_{\mathrm{q}}\right)$ in the monitoring stations along the Tsushima Warm Current. (a) Kagoshima, (b) Saga, (c) Shimane, (d) Fukui, (e) Ishikawa, (f) Niigata, (g) Aomori, (h) Tomari, (i) 314-01, (j) 105-11. Color indicates the collected time. 


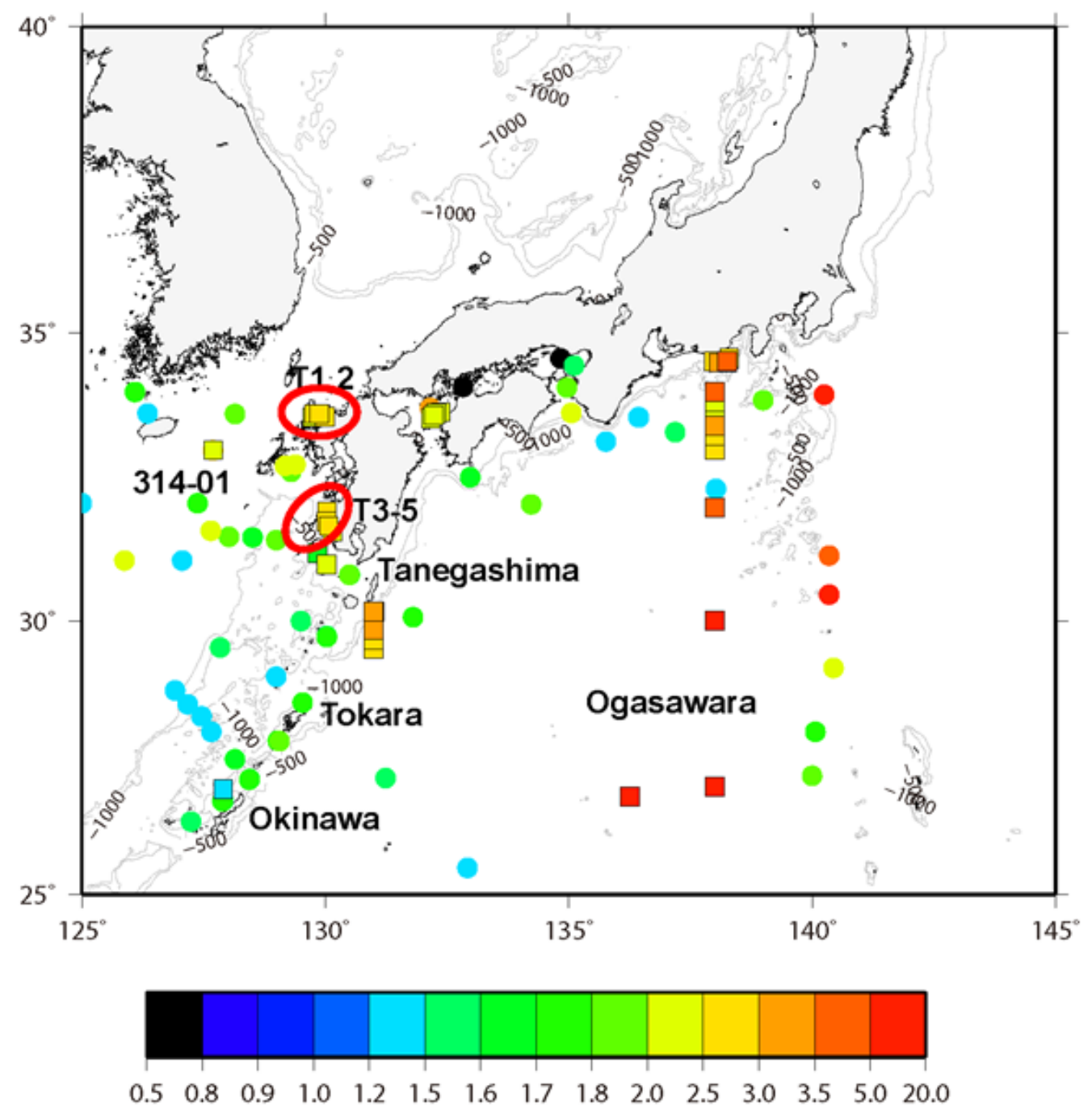

Figure S12. Horizontal distributions of ${ }^{137}$ Cs activity concentrations in the NPSJ and the ECS from 2011 to 2016. Circles mean the surface measurement data. Square denotes stations having vertical distribution. Unit is $\mathrm{Bq} \mathrm{m}^{-3}$. Higher activity concentrations around $25-30^{\circ} \mathrm{N}$ and $135-140^{\circ} \mathrm{E}$ were measured in the year of 2012. 


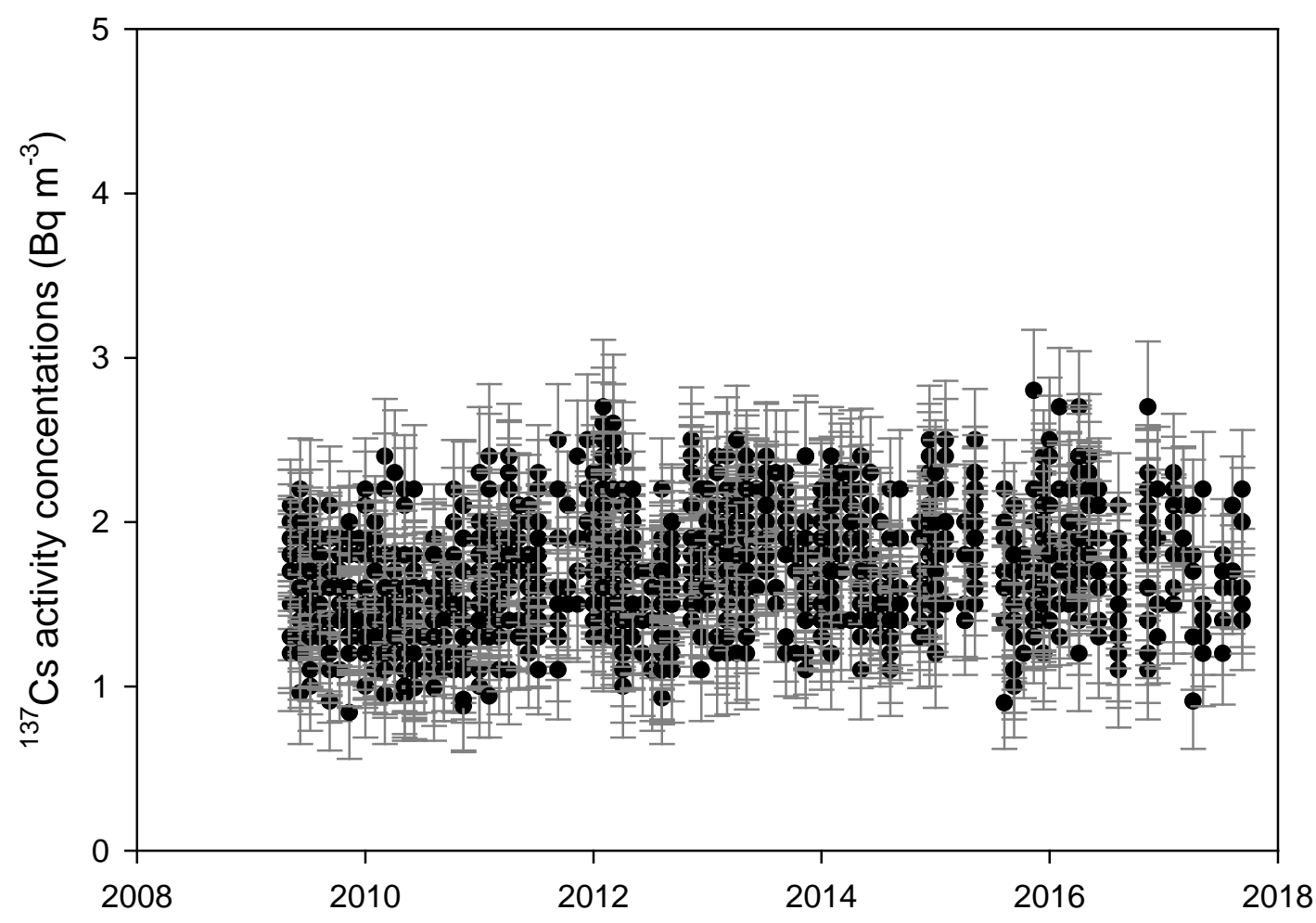

Figure S13: Temporal variations of ${ }^{137} \mathrm{Cs}$ activity concentrations at the station Okinawa from 2009 to 2017. 